\title{
CRA-E Panel on Undergraduate Research
}

Nancy M. Amato

Texas A\&M University

Dept. of CS and Engin.

College Station, TX 77843

amato@cse.tamu.edu

Ran Libeskind-Hadas

Harvey Mudd College

Dept. of Computer Science

Claremont, CA 91711

hadas@cs.hmc.edu

Panagiotis Takis Metaxas

Wellesley College

Dept. of Computer Science

Wellesley, MA02481

pmetaxas@wellesley.edu

Permission to make digital or hard copies of part or all of this work for personal or classroom use is granted without fee provided that copies are not made or distributed for profit or commercial advantage and that copies bear this notice and the full citation on the first page. Copyrights for third-party components of this work must be honored. For all other uses, contact the owner/author(s). Copyright is held by the author/owner(s). CSCW'15 Companion, March 14-18, 2015, Vancouver, BC, Canada. ACM 978-1-4503-2946-0/15/03.

http://dx.doi.org/10.1145/2685553.2699340

\begin{abstract}
This panel seeks to help faculty and other research mentors engage undergraduates in their research. The panel addresses the benefits of working with

undergraduates, funding opportunities, best practices in supervising undergraduate research, and finding additional resources. The panel is made possible by NSF Grant 1345291 to the Computing Research Association.
\end{abstract}

\section{Author Keywords}

Computer Science Undergraduate Research

\section{ACM Classification Keywords}

K [Computing Milieux]: K.3 COMPUTERS AND EDUCATION K.3.2 Computer and Information Science

Education.

\section{Introduction}

Graduate programs in computer science and related disciplines report that it is increasingly difficult to recruit U.S. citizens and permanent residents to to their Ph.D. programs. The fraction of domestic students receiving a Ph.D. from U.S. graduate programs has been below $50 \%$ since 2003 [1] and anecdotal evidence suggests that the rates are likely to continue declining for the foreseeable future. 
One promising approach to encourage and motivate bright undergraduates to pursue graduate studies and careers in research is to offer compelling undergraduate research experiences. Currently, the demand for research experiences greatly exceeds the supply.

Our objective is to help improve domestic undergraduate research pipeline by encouraging faculty to involve undergraduates in their research and to share effective practices that can make these research experiences positive for students and mentors alike.

\section{Panel Summary}

This panel session address four main topics: The benefits of working with undergraduates, funding opportunities, best practices in supervising undergraduate research, and finding additional resources. All resources and programs mentioned below are linked from the Conquer website (conquer.cra.org).

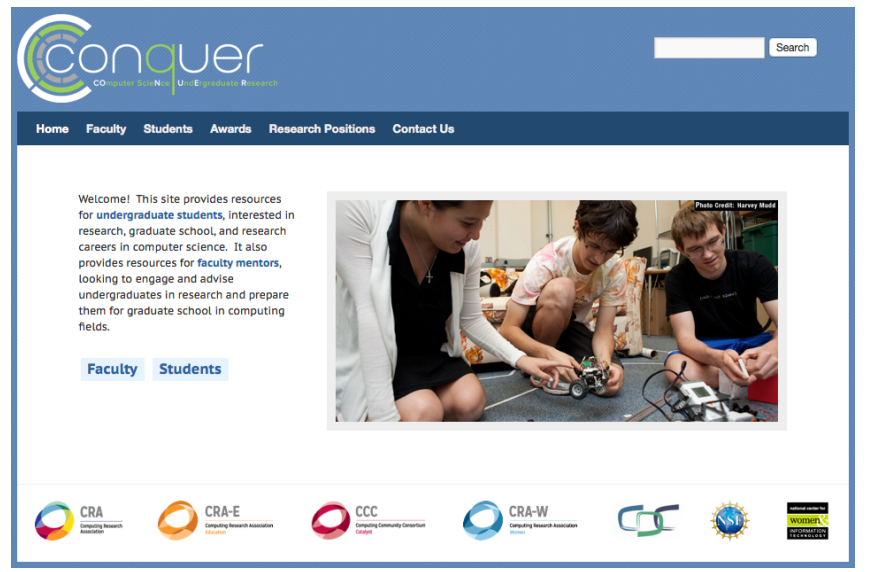

Figure 1: The Conquer (conquer.cra.org) site contains relevant information for both students and faculty.
The Benefits of Working With Undergraduates In this part of the session, panelists reflect on the benefits of working with undergraduate researchers. These include developing meaningful and long-lasting mentoring relationships, real benefits to the research program (including, in many cases, co-authored papers with undergraduates), a sense of contributing to the research community, and opportunities to identify and recruit excellent students to their departments doctoral program.

\section{Funding Opportunities}

While NSF REU sites provide support for a relatively large (e.g., 10 students per summer) cohort experience, there are many other funding opportunities that are often overlooked. Among these are:

- NSF REU Supplement awards. These awards are supplements to existing NSF research grants that are used to provide research stipends for undergraduates. The proposals are very short, the funding rates are relatively high, and the turn-around time for decisions is quick.

- The DREU (Distributed REU Program) administered by CRA-W and CDC matches promising undergraduate women and men from groups underrepresented in computing, including ethnic minorities and persons with disabilities, with a faculty mentor for a summer research experience at the faculty members institution. Funding includes summer research stipends and relocation travel assistance. Additional funds are available to support student conference travel, either during the summer or afterward.

- The CREU (Collaborative REU Program) funded by CRA-W and CDC provides funding for students from traditionally underrepresented groups to work on collaborative projects at their home institution. 


\section{Best Practices}

Panelists discuss best practices in supervising and

mentoring undergraduate researchers including:

- Choosing an appropriate problem

- Identifying and recruiting students

- Mentoring undergraduates during the research experience and beyond - including helping students apply for graduate school

\section{Additional Resources}

A number of resources are available for both students and research mentors. Among these are:

- Conquer (conquer.cra.org): This site is partitioned into two parts, one for students and one for faculty. The part for students provides information on summer research opportunities and advice (both general and practical) on graduate school in CS. For faculty, the site provides resources to help students find summer research positions, best practices on supervising summer research, and a slide deck on why and how to apply to graduate school, and more. Figure 1 shows the Conquer homepage.

- REU-in-a-box (http://www.ncwit.org/resources): This site provides an array of resources to help research mentors plan, execute, and assess undergraduate research experiences for undergraduates.

\section{Acknowledgements}

The panel is made possible by NSF Grant 1345291 to the Computing Research Association.

\section{References}

[1] Hambrusch, S., Libeskind-Hadas, R., Zhao, F.,

Rabson, D., Csizmar Dalal, A., Fox, E., Isbell, C., and Taylor, V. Exploring the baccalaureate origin of domestic ph.d. students in computing fields. Computing Research News 25, 1 (2013). 